\title{
Monovalent Fab' Immunoglobulin Fragments from Endemic Pemphigus Foliaceus Autoantibodies Reproduce the Human Disease in Neonatal Balb/c Mice
}

Barbara Rock, * Ramzy S. Labib, ${ }^{\star}$ and Luis A. Diaz ${ }^{\ddagger}$

${ }^{*}$ Department of Dermatology, Johns Hopkins University, Baltimore, Maryland 21216; and ${ }^{\ddagger}$ Department

of Dermatology, Medical College of Wisconsin, Milwaukee, Wisconsin 53226

\begin{abstract}
Fogo selvagem (FS) is an autoimmune disease caused by IgG autoantibodies to desmoglein I (DG-I), a desmosomal glycoprotein. We have previously shown that the autoantibodies in these patients are pathogenic and restricted mainly to the IgG4 subclass. The purpose of this study was to determine if the Fc domain or the valence of FS autoantibodies were relevant in the induction of epidermal disease in neonatal mice.

IgG4 was prepared from sera of FS patients by anion exchange chromatography, and digested with pepsin to yield F(ab')2 fragments. Monovalent FS Fab' were made by reduction and alkylation of FS F(ab')2. Intact FS IgG4, FS F(ab')2, and FS Fab' fragments were injected into neonatal mice. Intact FS IgG4 and both FS IgG fragments were pathogenic. The disease in the animals was dose dependent, and on the molar basis, FS Fab' fragments were more potent and efficient in producing disease than whole FS IgG.

These results suggest: $(a)$ simple binding of FS autoantibodies to DG-I may trigger keratinocyte detachment and epidermal disease; (b) DG-I may represent a keratinocyte cell adhesion molecule; and $(c)$ complement activation and surface cross-linking may not be relevant in keratinocyte detachment. (J. Clin. Invest. 1990. 85:296-299.) acantholysis • desmosomes • fogo selvagem • pemphigus
\end{abstract}

\section{Introduction}

We have recently reported that the IgG subclass autoantibody response in a large number of fogo selvagem (FS) ${ }^{1}$ patients $(n$ = 32) was preferentially IgG4 (1). Furthermore, passive

This work was presented in abstract form at the Annual Meeting of the Society for Investigative Dermatology, Washington, DC, on 29 April 1989.

Address reprint requests to Dr. L. A. Diaz, Department of Dermatology, Medical College of Wisconsin, 8701 Watertown Plank Rd., Milwaukee, WI 53226.

Received for publication 19 July 1989 and in revised form 7 September 1989.

1. Abbreviations used in this paper: FS, fogo salvagem; ICS, intercellular substance; IF, immunofluorescence; NHS, normal human sera.

J. Clin. Invest.

(C) The American Society for Clinical Investigation, Inc.

$0021-9738 / 90 / 01 / 0296 / 04 \$ 2.00$

Volume 85, January 1990, 296-299 transfer experiments carried out with purified FS IgG4 autoantibodies reproduced the human epidermal disease in neonatal mice (1). The molecular mechanisms by which FS IgG4 autoantibodies trigger keratinocyte detachment (acantholysis) in these animals remains to be determined.

The purpose of the present investigation was twofold. The first purpose was to study the pathogenic effect of proteolytic fragments of FS IgG4 autoantibodies that lack the Fc portion $\left[F\left(a b^{\prime}\right) 2\right.$ and $\left.F a^{\prime}\right]$. This would test the possibility of complement activation via the classical pathway as a mechanism of FS autoantibody injury of keratinocytes. The second purpose was to compare the pathogenic effect of the monovalent FS IgG Fab' fragments with those of intact, undigested FS IgG autoantibodies. This would explore the possibility that the simple binding of a keratinocyte surface antigen by monovalent FS Fab fragments is sufficient to precipitate acantholysis.

\section{Methods}

Source of sera. Two FS sera containing high titers of autoantibodies against the epidermal intercellular substance (ICS) were used throughout this investigation (1). The indirect immunofluorescence (IF) titer of FS autoantibodies in each serum was 1:640. These sera were obtained from two patients with active and generalized disease. Pooled normal human sera (NHS) were used as a source of normal IgG.

Total IgG from FS and NHS was prepared by $40 \%$ saturated ammonium sulfate precipitation. The IgG fractions were dissolved with pH 7.2 PBS, treated with protease inhibitors as described previously (1), and concentrated by ultrafiltration. FS autoantibodies of the IgG4 subclass were prepared from FS IgG by ion exchange chromatography as described previously (1).

IF techniques. The IgG subclass of FS autoantibodies present in FS sera was determined by indirect IF following procedures reported elsewhere $(1,2)$. FS autoantibodies (or murine $\mathrm{C} 3$ ) bound to murine epidermis were demonstrated by direct IF (1). Fluorescein-conjugated antisera reactive with human $F\left(a b^{\prime}\right) 2$ and $F c$ fragments and mouse $C 3$ were obtained commercially (Cappel Laboratories, West Chester, PA).

Preparation of $F\left(a b^{\prime}\right) 2$ and $F_{a b}$ fragments from FS IgG4 autoantibodies and normal human IgG. The IgG4-containing fraction of FS IgG was digested with pepsin (3) and the $F\left(a b^{\prime}\right) 2$ fragments purified by gel filtration chromatography using Sephacryl S-200 (Pharmacia, Uppsala, Sweden). Fab' fragments were prepared by reduction of $\mathrm{F}\left(\mathrm{ab}^{\prime}\right) 2$ fragments with $0.01 \mathrm{M}$ DTT at $\mathrm{pH} 8.7$ and alkylation with 0.02 $\mathrm{M}$ iodoacetamide (4). FS autoantibody activity in these fractions was tested by indirect IF using antihuman FITC-labeled antisera specific for human $F\left(a^{\prime}\right) 2$ and $F c$ fragments. IgG fragments were monitored by SDS-PAGE under reduced and unreduced conditions. Fab' fragments from normal human IgG were prepared similarly.

Passive transfer of FS IgG, FS F(ab')2, and FS Fab' to neonatal mice. Neonatal Balb/c mice were injected subcutaneously with $0.1 \mathrm{ml}$ of filter-sterilized PBS solutions of IgG, $\mathrm{F}\left(\mathrm{ab}^{\prime}\right) 2$, and $\mathrm{Fab}^{\prime}$ prepared 
from FS and control NHS $(1,5)$. Each solution was tested in duplicate using the following amounts of protein per gram of body weight: intact IgG4 (7.3 mg), F(ab')2 (4.0 mg), and Fab' (3.2 mg), respectively.

To compare the pathogenic effect of FS IgG and the Fab' fragment prepared from the same FS serum, the animals were injected with a range of doses of FS IgG (0.20-15 mg/g body weight) and its Fab fragment $(0.08-5 \mathrm{mg} / \mathrm{g}$ body weight). The indirect IF titer of FS autoantibodies of a solution of $\sim 1 \mathrm{mM}$ FS IgG and FS Fab' was 1:12,800.

The skin and serum of neonatal mice injected with IgG and IgG fragments were evaluated clinically, histologically, and immunologically at 7 and $24 \mathrm{~h}(1,5)$

\section{Results}

Passive transfer of FS IgG4 and its $F\left(a b^{\prime}\right) 2$ and $F a b^{\prime}$ fragments induces disease in neonatal mice. All neonatal BALB/c mice injected with FS IgG4 and the $F\left(a b^{\prime}\right) 2$ and $\mathrm{Fab}^{\prime}$ fragments derived from the same FS IgG developed disease. These results were reproduced in duplicate littermate animals at least three times for each of the antibody fractions. Clinically, the skin of these animals developed extensive erosions, which on histological examination revealed vesicle formation through the granular cell layer. The pathological changes induced by FS IgG and IgG fragments at $24 \mathrm{~h}$ were indistinguishable clinically or histologically. The diseased epidermis of the animals showed human FS IgG4 or FS IgG fragments bound to the ICS by direct IF. The typical clinical, histological, and immunological findings in a neonatal mouse injected with Fab' fragments de- rived from FS IgG4 are shown in Fig. 1. Panels $c$ and $d$ of this figure show that the bound $\mathrm{Fab}^{\prime}$ fragments are recognized only by FITC-conjugated antihuman $F\left(a b^{\prime}\right) 2$ serum and not by FITC antisera specific for the Fc portion of IgG. Normal human IgG or IgG fragments derived from NHS were harmless to the experimental animals. Murine $\mathrm{C} 3$ was not detected in the epidermis of mice injected with either FS IgG4 or FS IgG4 fragments but was weakly detected in the epidermal ICS of animals injected with unfractionated whole FS IgG. These specimens also showed a nonspecific granular/linear deposition of $\mathrm{C} 3$ along the dermal-epidermal junction.

The sera of animals injected with FS IgG4 and FS IgG4 fragments showed titers of human antiepidermal autoantibodies above $1: 320$ by $24 \mathrm{~h}$ when all animals exhibited epidermal disease.

The pathogenic activity of FS Fab' is more potent than FS $I g G$. The major differences found in experimental animals injected with either FS IgG or FS Fab' were in the doses of protein required to induce epidermal disease and in the timing of the onset of detectable epidermal disease in the animals. As seen in Table I mice injected with FS Fab' developed skin lesions as early as $7 \mathrm{~h}$ after injection and with as little as 0.32 $\mathrm{mg}$ of protein, whereas mice injected with FS IgG did not develop lesions by $7 \mathrm{~h}$ with higher doses of $\operatorname{IgG}(15 \mathrm{mg})$. However, all animals injected with higher doses of FS IgG (7.5 and $15 \mathrm{mg}$ ) developed epidermal disease by $24 \mathrm{~h}$ after injection. This table also shows that titers of FS autoantibody activity by
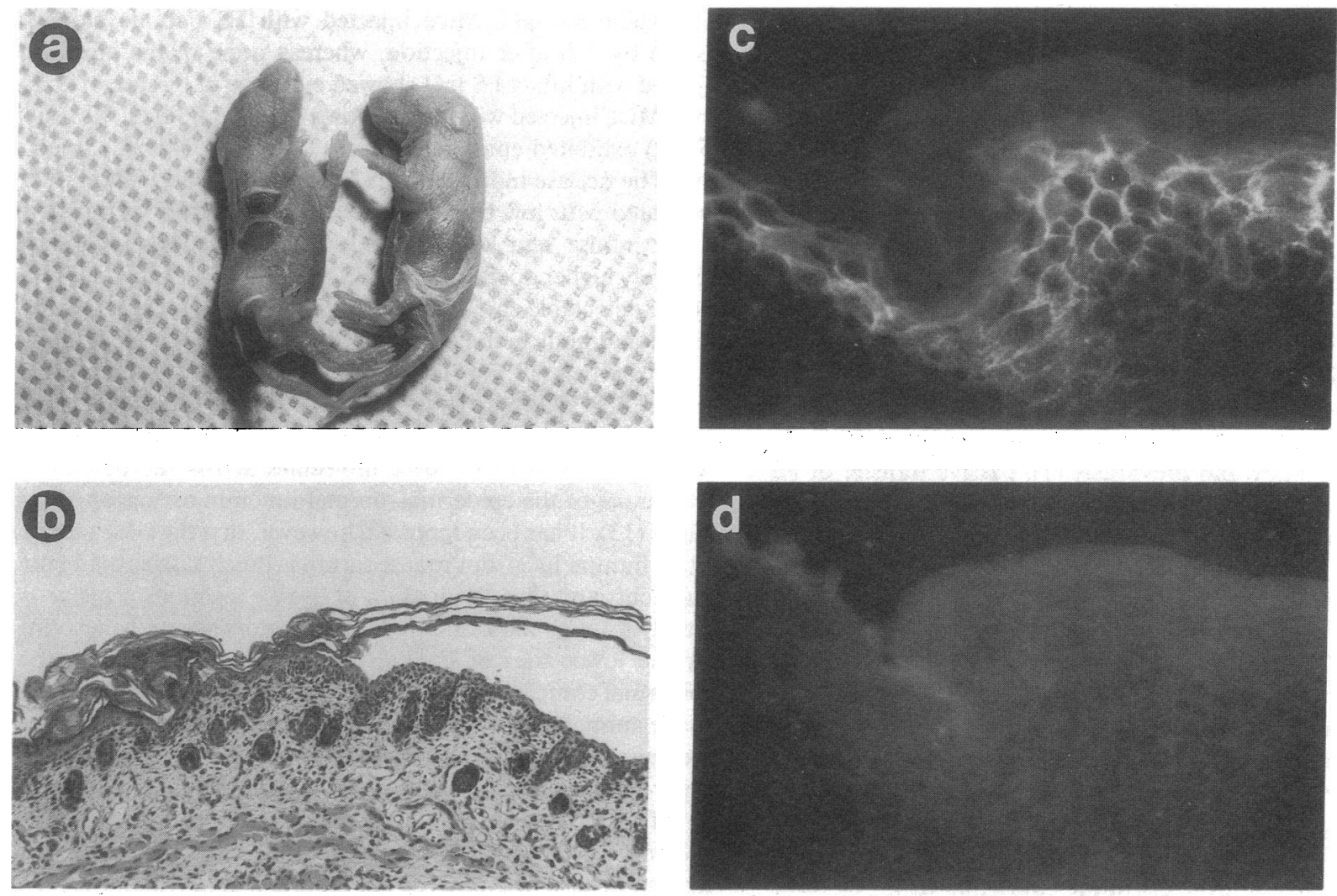

Figure 1. (a) Neonatal Balb/c mice at $7 \mathrm{~h}$ after the injection of FS Fab' fragments showing extensive erosions of the skin. (b) Hematoxylin/eosin stained section of lesional skin showing subcorneal vesiculation. (c) Direct IF of lesional skin using fluorescein-conjugated antihuman $F\left(a b^{\prime}\right) 2$ serum demonstrating staining of the ICS. (d) Direct IF procedure of lesional skin using fluorescein-conjugated antihuman Fc serum showing negative results. 
Table I. Pathogenicity of Various Doses of FS IgG and FS Fab' to Neonatal Balb/c Mice at 7 h after Injection

\begin{tabular}{|c|c|c|c|c|c|c|c|}
\hline \multicolumn{4}{|c|}{ Intact FS IgG } & \multicolumn{4}{|c|}{ FS Fab' } \\
\hline \multicolumn{2}{|c|}{ Doses injected } & \multirow[t]{2}{*}{ Disease induced ${ }^{*}$} & \multirow[t]{2}{*}{$\begin{array}{l}\text { Indirect IF titer } \\
(\text { mouse serum })^{\ddagger}\end{array}$} & \multicolumn{2}{|c|}{ Doses injected } & \multirow[t]{2}{*}{ Disease induced ${ }^{*}$} & \multirow[t]{2}{*}{$\begin{array}{l}\text { Indirect IF titer } \\
\text { (mouse serum) }\end{array}$} \\
\hline$m g$ & nmol & & & $m g$ & nmol & & \\
\hline 15.00 & 100.00 & $(-)$ & $1: 320$ & 5.00 & 100.00 & $(+)$ & $1: 1280$ \\
\hline 7.50 & 50.00 & $(-)$ & $1: 320$ & 2.50 & 50.00 & $(+)$ & $1: 320$ \\
\hline 3.75 & 25.00 & $(-)$ & $1: 320$ & 1.25 & 25.00 & $(+)$ & $1: 160$ \\
\hline 1.87 & 12.50 & $(-)$ & $1: 160$ & 0.62 & 12.50 & $(+)$ & $1: 40$ \\
\hline 0.93 & 6.25 & $(-)$ & $1: 80$ & 0.31 & 6.25 & $(+)$ & $1: 20$ \\
\hline \multirow[t]{2}{*}{0.46} & 3.12 & $(-)$ & $1: 20$ & 0.16 & 3.12 & $(-)$ & Negative \\
\hline & & & & 0.08 & 1.65 & $(-)$ & Negative \\
\hline
\end{tabular}

* Animals showing normal skin are designated (-), and those exhibiting vesicles, erosions, and a positive Nikolsky sign are designated (+).

${ }^{\ddagger}$ Human FS autoantibody activity present in the mouse sera at the time of killing.

indirect IF in mice injected with FS Fab' and exhibiting epidermal disease by $7 \mathrm{~h}$ were as low as $1: 20$, whereas titers as high as 1:320 were reached in animals injected with intact FS IgG exhibiting normal epidermis at the same time. These experiments were carried out in duplicate animals and reproduced twice.

\section{Discussion}

FS is the endemic form of pemphigus foliaceus reported since the beginning of the century in certain states of Brazil and thought to be precipitated by an environmental factor (6). The disease shares similar clinical and immunopathological features with the nonendemic form of pemphigus foliaceus seen in the rest of the world (7). All FS patients possess disease-specific autoantibodies against the epidermal ICS (8). We have shown that FS autoantibodies are pathogenic by passive transfer $(1,5)$ and restricted to the IgG4 subclass (1). The epidermal antigenic moiety recognized by FS autoantibodies has been shown to be present in a desmosomal core glycoprotein named desmoglein I (9). The mechanisms by which FS autoantibodies cause epidermal disease remain unknown.

The role of complement activation in the epidermal injury caused by FS autoantibodies appears to be minimal. First, as shown in this study and previously (1), passive transfer of FS IgG4 produced epidermal disease in neonatal mice, and IgG4 antibodies are known to be poor complement activators (10). Second, this study also shows that FS IgG fragments [Fab' and $\mathrm{F}\left(\mathrm{ab}^{\prime}\right) 2$ ] which lack the complement binding site are also pathogenic to mice. These findings therefore suggest that in vivo, FS IgG subclasses other than IgG4, present in FS serum, may fix complement to the epidermal ICS and amplify epidermal disease (11). This possibility is in agreement with our findings, which showed that mice injected with unfractionated FS IgG developed disease and exhibited murine C3 bound to the epidermal ICS, whereas animals injected with FS IgG4 or its proteolytic fragments also developed epidermal disease but had undetectable murine $\mathrm{C} 3$ in the epidermal ICS.

Based on immunoelectron microscopic findings, Patel et al. (12) concluded that the earliest triggering mechanism of acantholysis in pemphigus vulgaris, a close-related disease, is the autoantibody-induced cross-linking of surface antigens.
These complexes are subsequently internalized into intracellular lysosomes. The present investigation, however, showed that this phenomenon may not be relevant in the acantholysis induced by FS autoantibodies because passive transfer of monovalent FS Fab' was far superior than intact FS IgG in inducing epidermal disease in neonatal mice.

As shown in Table I, on the basis of equimolar binding sites, smaller doses of FS Fab' than intact FS IgG were able to induce epidermal disease. Further, the onset of disease in Fab'-injected animals occurred earlier than in mice injected with whole FS IgG. Mice injected with FS Fab' developed disease by $7 \mathrm{~h}$ after injection, whereas none of the animals injected with intact FS IgG showed evidence of disease by this time. Mice injected with higher doses of intact FS IgG (7.5 and $15 \mathrm{mg}$ ) exhibited epidermal disease only $24 \mathrm{~h}$ after the injection. The disease induced by FS Fab' was dose dependent and associated with low titers of human FS autoantibody activity in the mouse sera at $7 \mathrm{~h}(1: 20)$. This was surprising since relatively higher doses of intact FS IgG $(7.5$ and $15 \mathrm{mg})$ did not induce detectable epidermal disease by $7 \mathrm{~h}$ but showed titers of FS autoantibody activity above 1:80 in this same time period. It appears that FS Fab' diffuses from the serum into the epidermal ICS causing disease faster and more efficiently than intact FS IgG molecules. Molecular size or charge may regulate the permeation of these molecules across the basement membrane of the epidermal-dermal junction as suggested by others (13). It has been reported, however, that the clearance of intact human IgG from mouse serum is much slower than $\mathrm{Fab}^{\prime}$ fragments and that elimination of these exogenous proteins is mainly through the kidney (14). Two factors appear to account for the lower titer of FS $\mathrm{Fab}^{\prime}$ at the 7-h diffusion into the epidermal compartment and clearance from the vascular pool. In the animal model, the FS Fab' is rapidly cleared through the kidney and quickly diffuses into the epidermis, resulting in lower titers of autoantibody activity in the mouse serum compared with the intact FS IgG. Intravascular degradation of FS IgG into Fab' fragments does not appear to be relevant to the human disease inasmuch as our studies indicate that intact FS IgG also enters the epidermal compartment and causes acantholysis, but at a much slower rate.

The mechanism by which FS Fab' causes keratinocyte detachment is open to further studies. Binding of a keratinocyte 
surface molecule appears to play a role in the disease. Borondes (15) listed certain criteria that a molecule should fulfill in order to be considered a cell adhesion molecule. These criteria are: $(a)$ it should be located on the cell surface; $(b)$ the appearance of the cell-surface molecule correlates with the development of adhesiveness; $(c)$ they should have complementary receptors on the cell surface; $(d)$ binding of univalent antibodies (Fab') blocks cell adhesion; and (e) that mutants with impaired cell adhesion should have defective cell adhesion molecule. It is known that FS autoantibodies recognize desmoglein I which is a transmembrane molecule with a surface-exposed domain (16), and as shown in this study, monovalent $\mathrm{FS} \mathrm{Fab}^{\prime}$ induces keratinocyte detachment when passively transferred to neonatal mice. These preliminary observations suggest that the epitopes recognized by FS autoantibodies on the desmoglein molecule may indeed be related to keratinocyte adhesion. FS autoantibodies may bind these epitopes and trigger acantholysis as previously postulated $(17,18)$.

\section{Acknowledgments}

This work was supported in part by U. S. Public Health Service grants R01-AR32599, R01-AR32081, F06 TW12222-01, and T32-AR07324 from the National Institutes of Health, and a research grant awarded by the Dermatology Foundation.

\section{References}

1. Rock, B., G. J. Anhalt, R. S. Labib, C. R. Martins, E. A. Rivitti, A. N. Theofilopoulos, and L. A. Diaz. 1989. Restricted heterogeneity of IgG subclasses in fogo selvagem (endemic pemphigus foliaceus). $N$. Engl. J. Med. 320:1463-1469.

2. Matis, W. L., G. J. Anhalt, L. A. Diaz, E. A. Rivitti, C. R. Martins, and R. S. Berger. 1987. Calcium enhances the sensitivity of immunofluorescence for pemphigus antibodies. J. Invest. Dermatol. 89:302-304.

3. Turner, M. W., H. H. Bennick, and J. B. Natvig. 1970. Simple method of subtyping human G-myeloma proteins based on sensitivity to pepsin digestion. Nature (Lond.). 225:853-855.

4. Diaz, L. A., H. P. Patel, and N. J. Calvanico. 1979. Bullous pemphigoid antigen. II. Isolation from the urine of a patient. J. Immunol. 122:605-608.

5. Roscoe, J. T., L. A. Diaz, S. A. P. Sampaio, R. M. Castro, R. S. Labib, Y. Takahashi, H. P. Patel, and G. J. Anhalt. 1985. Brazilian pemphigus foliaceus autoantibodies are pathogenic to BALB/c mice by passive transfer. J. Invest. Dermatol. 85:538-541.

6. Diaz, L. A., S. A. P. Sampaio, E. A. Rivitti, C. R. Martins, P. R. Cunha, C. Lombardi, F. A. Almeida, R. Martins-Castro, M. L. Macca, C. Lavrado, G. H. Filho, P. C. Borges, A. Chaul, L. Minelli, J. C. Empinotti, H. Friedman, I. Campbell, R. S. Labib, and G. J. Anhalt. 1989. Endemic pemphigus foliaceus (fogo selvagem). II. Current and historic epidemiologic studies. J. Invest. Dermatol. 92:4-12.

7. Diaz, L. A., S. A. P. Sampaio, E. A. Rivitti, C. R. Martins, P. R. Cunha, C. Lombardi, F. A. Almeida, R. Martins-Castro, M. L. Macca, C. Lavrado, G. H. Filho, P. C. Borges, A. Chaul, L. Minelli, J. C. Empinotti, H. Friedman, I. Campbell, R. S. Labib, and G. J. Anhalt. 1989. Endemic pemphigus foliaceus (fogo selvagem). I. Clinical features and immunopathology. J. Am. Acad. Dermatol. 20:657-669.

8. Squiquera, H. L., L. A. Diaz, S. A. P. Sampaio, E. A. Rivitti, C. R. Martins, P. R. Cunha, C. Lombardi, C. Lavrado, G. H. Filho, P. C. Borges, H. Friedman, R. S. Labib, G. J. Anhalt, and the Cooperative Group on Fogo Selvagem Research. 1988. Serological abnormalities in patients with endemic pemphigus foliaceus (fogo selvagem), their relatives and normal donors from endemic and non-endemic areas of Brazil. J. Invest. Dermatol. 91:189-191.

9. Stanley, J. R., L. Koulu, V. Klaus-Kovtun, and M. S. Steinberg. 1986. A monoclonal antibody against the desmosomal glycoprotein desmoglein I binds the same polypeptide as human autoantibodies in pemphigus foliaceus. J. Immunol. 136:1227-1230.

10. Schur, P. H. 1987. IgG subclasses. Ann. Allergy. 58:89-99.

11. Kawana, S., L. A. Diaz, E. A. Rivitti, W. D. Geoghegan, and R. E. Jordon. 1988. Complement fixation by Brazilian pemphigus foliaceus autoantibodies. Clin. Exp. Immunol. 71:464-469.

12. Patel, H. P., L. A. Diaz, G. J. Anhalt, R. S. Labib, and Y. Takahashi. 1984. Demonstration of pemphigus antibodies on the cell surface of murine epidermal cell monolayers and their internalization. J. Invest. Dermatol. 83:409-415.

13. Ohkubo, T., and S. Sano. 1973. Functional aspects of the dermo-epidermal junction. Acta Dermatovenerol. 73:121-128.

14. Spiegelberg, H. L., and W. O. Weigle. 1965. The catabolism of homologous and heterologous $7 \mathrm{~S}$ gamma globulin fragments. J. Exp. Med. 121:323-338.

15. Borondes, S. H. 1980. Endogenous cell-surface lectins: evidence that they are cell adhesion molecules. In The Cell Surface: Mediator of Developmental Processes. S. Subtelny and N. K. Wessells, editors. Academic Press, New York. 349-363.

16. Schmelz, M., R. Duden, P. Cowin, and W. W. Franke. 1986. A constitutive transmembrane glycoprotein of $M_{r} 165,000$ (desmoglein) in epidermal and non-epidermal desmosomes. II. Immunolocalization and microinjection studies. Eur. J. Cell Biol. 42:184-199.

17. Diaz, L. A., and C. L. Marcelo. 1979. Pemphigus and pemphigoid antigens in cultured epidermal cells. Br. J. Dermatol. 98:631-637.

18. Diaz, L. A. 1979. Molecular structure of the epidermal extracellular spaces. A review. Int. J. Dermatol. 18:432-442. 